\title{
Ribotype 027 Clostridium difficile infections with measurable stool toxin have increased lactoferrin and are associated with a higher mortality
}

\author{
J. H. Boone • L. R. Archbald-Pannone • K. N. Wickham • \\ R. J. Carman • R. L. Guerrant • C. T. Franck • \\ D. M. Lyerly
}

Received: 28 October 2013 / Accepted: 20 December 2013 /Published online: 22 January 2014

(C) The Author(s) 2014. This article is published with open access at Springerlink.com

\begin{abstract}
We evaluated clinical and diagnostic indicators of severe $C$. difficile infection (CDI) and their association with poor clinical outcome. A total of 210 patients positive according to PCR (toxin B: $t c d \mathrm{~B}$ ) were included, with patients having a median age of 62 years and a Charlson comorbidity index (CI) score of 5. Ninety-one percent $(n=191)$ were positive by toxigenic culture and $61 \%(n=129)$ had stool toxin. Toxin-positive patients had significantly higher fecal lactoferrin (mean $316 \mu \mathrm{g} / \mathrm{g}$ versus $106 \mu \mathrm{g} / \mathrm{g}$ stool; $p<0.0001$ ). Forty percent of patients $(n=85)$ were infected with ribotype 027 and significantly more of these patients had measurable stool toxin $(79 \%$ vs. $50 \% ; p<0.0001)$. The mean fecal lactoferrin was significantly higher for toxin-positive 027 CDI compared with the 027 toxin-negative group (317 vs $60 \mu \mathrm{g} / \mathrm{g} ; p=0.0014)$. Ribotype 027 CDI with stool toxin showed a higher all-cause, 100-day mortality compared with non-027 with stool toxin ( $36 \%$ vs $18 \% ; p=0.017$ ). Logistic regression univariate analysis for odds ratio (OR) and $p$ values revealed that age $(\mathrm{OR}=1.1)$, intensive care unit treatment $(\mathrm{OR}=2.7)$, $\mathrm{CI}(\mathrm{OR}=1.2), 027 \mathrm{CDI}(\mathrm{OR}=2.1)$, white blood cell count $(\mathrm{OR}=1.0)$, albumin level $(\mathrm{OR}=0.1)$, and stool toxin-positive $027 \mathrm{CDI}(\mathrm{OR}=2.5)$ were significantly associated with 100 -day mortality $(p<0.05)$. In conclusion, CDI
\end{abstract}

\footnotetext{
J. H. Boone $(\bowtie) \cdot$ K. N. Wickham $\cdot$ R. J. Carman · D. M. Lyerly Research and Development, TechLab, Inc., 2001 Kraft Drive, Blacksburg, VA 24060, USA

e-mail: jhboone@techlab.com

L. R. Archbald-Pannone • R. L. Guerrant

Department of Internal Medicine, University of Virginia,

Charlottesville, VA 22908, USA

C. T. Franck

Department of Statistics, Virginia Tech, Blacksburg, VA 24061, USA
}

PCR-positive patients with 027 infection and stool toxin have increased lactoferrin and are at an increased risk of death.

\section{Introduction}

C. difficile infection (CDI) is a common complication for hospitalized patients. Identifying and appropriately treating patients who are more likely to suffer poor outcomes from this infection would improve clinical outcome and decrease healthcare costs. In the United States, the mortality rate from CDI has increased from 5.7 deaths per million people in 1999 to 23.7 deaths per million in 2004 [1]. The emergence of ribotype $027 \mathrm{BI} / \mathrm{NAP} 1$ in the early 2000 s has led to outbreaks of CDI with more severe disease and an increased death rate in hospitalized patients [2-9]. The increased severity and transmission seen with the ribotype 027 has correlated with a combination of elevated early in vitro toxin production, increased sporulation, efficient germination, and resistance to fluoroquinolones [10-15]. Even though this strain has continued to increase in prevalence, the association with more severe disease is not consistent among studies, raising questions as to what cofactors contribute to severe CDI and worse outcomes [16-20]. Further studies are needed to target more accurately the combination of variables that contribute to severe infections and poor outcomes following CDI.

Laboratory diagnosis of $\mathrm{CDI}$ has changed over recent years resulting in molecular testing for the toxin genes (tcdA and $t c d B$ ) becoming more common in the United States, while the detection of toxin continues to be the test of choice in Europe $[21,22]$. Both methods offer advantages. Molecular assays are highly sensitive showing between a true-positive rate of 75 and $85 \%$ for toxigenic culture in many comparative studies 
[21]. GDH detection and toxin enzyme-linked immunoassay (EIA) tests, on the other hand, indicate the presence of the actively growing vegetative toxigenic $C$. difficile and correlate with worse outcome $[23,24]$. These different tests have generated an increasing need for defined clinical criteria and host biomarkers that accurately identify patients who require aggressive treatment.

Various clinical criteria and blood biomarkers have been associated with increased CDI severity and poor clinical outcome. These factors include age, medical co-morbidities, clinical symptoms of fever and abdominal pain, increased peripheral white blood cell count (WBC), elevated serum creatinine, and low serum albumin [25-32]. C. difficile toxins act locally to create intense intestinal inflammation that can be seen by colonoscopy or radiographic imaging, or measured in stool by fecal leucocytes or elevated fecal lactoferrin [19, 33-36]. More recently, fecal lactoferrin and fecal IL-8, both biomarkers of inflammation, have been shown to identify more severe cases of CDI [37-40]. In our study, we evaluated a novel combination of patient characteristics, clinical laboratory results, and fecal parameters with the infecting ribotype to evaluate their relationship with poor clinical outcome, as measured by 100 -day, all-cause mortality for hospitalized patients positive for $C$. difficile according to PCR.

\section{Materials and methods}

\section{Study subjects}

Sequential in-patients from May 2010 to August 2011 with a clinical diagnosis of CDI and positive for $t c d B$ according to PCR (BD GeneOhm C diff Assay, Becton Dickinson, Franklin Lakes, NJ, USA, or Xpert C. difficile, Cepheid, Sunnyvale, CA, USA) were identified according to the protocol (HSR-IRB \#13630, NIH/NIAID 5K23A1074681). Patients were deemed eligible if hospitalized at the time of CDI diagnosis, $\geq 18$ years old, no recent history of chronic diarrhea ( $\geq 4$ weeks), and adequate volume of stool for subsequent testing. Enrolled subjects were followed for clinical outcome by review of medical records and telephone contact following diagnosis.

\section{Chart reviews}

Reviews of medical records were carried out by participating clinical research team members to record patient demographics, medical co-morbidities, and clinically obtained blood and serum laboratory results (peripheral white blood cell count, serum albumin, and serum creatinine) at the time of CDI diagnosis. During hospitalization, all-cause treatment in the intensive care unit (ICU) and 100-day, all-cause mortality were recorded. An age-unadjusted Charlson co-morbidity
Index score for assessing co-morbid disease was calculated for each patient, as described previously [41, 42].

Toxin detection

C. difficile testing was done at the hospital clinical microbiology laboratory using $t c d B$ PCR (BD GeneOhm C diff Assay, Becton Dickinson, or Xpert $C$. difficile, Cepheid) according to the manufacturer's instructions. A fecal specimen from eligible $t c d B$-positive subjects on the day of CDI diagnosis was frozen at $-80{ }^{\circ} \mathrm{C}$ and shipped to TechLab, Blacksburg, VA, USA, for biomarker testing and toxigenic culture, as well as PCR ribotyping. Stool toxin B was detected by tissue culture using the C. DIFFICILE TOX-B Test (TechLab ${ }^{\circledR}$ Inc., Blacksburg, VA) including a neutral goat serum control as described by Boone et al. [37]

Fecal lactoferrin analysis

The amount of fecal lactoferrin $(\mu \mathrm{g} / \mathrm{g}$ stool) was quantitatively determined using the IBD-SCAN ${ }^{\circledR}$ test, according to the package insert $\left(\right.$ TechLab $\left.{ }^{\circledR}\right)$.

\section{Bacterial culture and ribotyping}

Toxigenic culture was obtained using the ethanol shock method previously described by Boone et al. [43] and C. difficile isolates were evaluated for PCR ribotype using the procedure developed by Stubbs et al. [44].

\section{Statistical analysis}

A summary was tabulated to describe patient demographic and diagnostic characteristics. In cases where a skew was above 1.5 in magnitude (i.e. greater than 1.5 or less than 1.5), medians and ranges were reported. Otherwise, means and standard deviations (sd) were provided. Significance testing for percentage differences was based on Fisher's Exact Test and Wilcoxon rank sum test for continuous variables. Logistic regression was used to assess the bivariate relationships between 100-day all-cause mortality and the available clinical and lab results. A predictive model was formed in the logistic regression framework using the Bayesian Information Criteria (BIC) to determine a parsimonious subset of variables which were highly predictive of 100-day all-cause mortality. Predictive accuracy was assessed using the concordance index, or c-statistic, which measures the tradeoff between true positive and false positive rates across the range of model predictions. The c-statistic is defined between zero and one. A c-statistic of 0.5 corresponds to a diagnostic rule as effective as a coin flip, and higher c-statistics are better. A significant difference was defined as having a $p$-value of $\leq 0.05$. 


\section{Results}

A total of 210 adult hospitalized patients who tested positive for $C$. difficile according to PCR (for $t c d B$ ) were enrolled. The cohort was $50 \%(n=105)$ female, mean age was 60.4 $(\mathrm{sd}=16.8)$ years and $44 \%(n=93)$ were $\geq 65$ years old. The mean Charlson co-morbidity index score was $5(\mathrm{sd}=3)$ points and the most frequently reported co-morbid conditions included $46 \%(n=96)$ having moderate to severe renal failure and $34 \%(n=72)$ suffering with dementia. A $63 \%$ majority of subjects $(n=132)$ had a score of $>3$ points using the Charlson co-morbidity index. Ninety-five subjects (45\%) were treated in the intensive care unit (ICU) during this hospitalization and

Table 1 Patient characteristics. Mean and standard deviation are reported for continuous variables. The skew for all continuous variables was below 1.5 in magnitude. Sample sizes ranged from 206 to 210 for these measures

\begin{tabular}{|c|c|c|}
\hline Patient characteristics & Frequency & Percent \\
\hline \multicolumn{3}{|l|}{ Age in years, mean $=60.4, \mathrm{sd}=16.8$} \\
\hline$<65$ & 117 & 55.7 \\
\hline$\geq 65$ & 93 & 44.3 \\
\hline Male gender & 105 & 50 \\
\hline \multicolumn{3}{|l|}{ Charlson index, mean $=4.9, \mathrm{sd}=2.9$} \\
\hline 0 & 7 & 3.3 \\
\hline $1-3$ & 71 & 33.8 \\
\hline $4-6$ & 79 & 37.6 \\
\hline$>6$ & 53 & 25.2 \\
\hline \multicolumn{3}{|l|}{ Comorbidities } \\
\hline Myocardial infarction & 54 & 25.7 \\
\hline Congestive heart failure & 51 & 24.3 \\
\hline Peripheral vascular disease & 24 & 11.4 \\
\hline Cerebrovascular disease & 31 & 14.8 \\
\hline Dementia/delirium & 72 & 34.3 \\
\hline Connective tissue disorder & 16 & 7.6 \\
\hline Chronic pulmonary dysfunction & 49 & 23.3 \\
\hline Gastric ulcer disease & 32 & 15.2 \\
\hline Mild liver disease & 17 & 8.1 \\
\hline Diabetes (no end organ damage) & 37 & 17.6 \\
\hline Hemiplegia & 16 & 7.7 \\
\hline Moderate-severe renal disease & 96 & 46.2 \\
\hline Diabetes with end organ damage & 28 & 13.4 \\
\hline Any tumor & 60 & 28.6 \\
\hline Leukemia & 5 & 2.4 \\
\hline Lymphoma & 7 & 3.4 \\
\hline Moderate to severe liver disease & 28 & 13.5 \\
\hline Metastatic solid tumor & 20 & 9.7 \\
\hline AIDS & 3 & 1.4 \\
\hline Intensive care unit & 95 & 45.2 \\
\hline 100-day mortality & 50 & 23.8 \\
\hline
\end{tabular}

Table 2 Diagnostic parameters. Frequencies and percentages are reported for categorical variables. Sample sizes range between 207 and 210 except for albumin, which has a sample size of $n=162$

\begin{tabular}{lc}
\hline Diagnostic parameters & Frequency $(\%)$ \\
\hline PCR + & $210(100)$ \\
Tissue culture + & $129(61.4)$ \\
Toxigenic culture + & $191(91.0)$ \\
Ribotype 027 CDI & $85(40.5)$ \\
White blood cell count & \\
$<10 \times 10^{9} / \mathrm{L}$ & $89(42.6)$ \\
$10,000-15,000 \times 10^{9} / \mathrm{L}$ & $52(24.9)$ \\
$>15 \times 10^{9} / \mathrm{L}$ & $68(32.5)$ \\
Lactoferrin & \\
$<7.25, \mu \mathrm{g} / \mathrm{g}$ & $49(23.3)$ \\
$7.25-100 \mu \mathrm{gg} / \mathrm{g}$ & $83(39.5)$ \\
$>100 \mu \mathrm{g} / \mathrm{g}$ & $78(37.1)$ \\
Albumin level & \\
$<2.5 \mathrm{~g} / \mathrm{dL}$ & $33(20.4)$ \\
$\geq 2.5 \mathrm{~g} / \mathrm{dL}$ & $129(79.6)$ \\
Creatinine & \\
$<1.5 \mathrm{mg} / \mathrm{dL}$ & $148(71.5)$ \\
$\geq 1.5 \mathrm{mg} / \mathrm{dL}$ & $59(28.5)$ \\
\hline
\end{tabular}

50 subjects $(24 \%)$ died within 100 days of CDI diagnosis, with a mean of $36(\mathrm{sd}=29)$ days until death. The recorded cause of death for the 50 subjects included 15 (30\%) unknown, 14 (28\%) sepsis with 2 documented as CDI sepsis, 6 (12\%) malignancy, 5 (10\%) respiratory failure, 4 (8\%) liver disease, 4 (8\%) congestive heart failure, and 2 (4\%) infection. The patient demographics and clinical characteristics are listed in Table 1.

Based on stool studies for CDI, $91 \%$ of subjects $(n=191)$ were positive by toxigenic culture, and stool toxin, as determined by tissue culture, was detected in $61 \%(n=129)$. The top 5 most prevalent toxigenic ribotypes in this patient cohort were ribotype 027 at $40 \%(n=85)$, ribotype 014 at $10 \%(n=20)$, ribotype 106 at $6 \%(n=12)$, ribotype 056 at $6 \%(n=12)$, and ribotype 053 at $5 \%(n=9)$.

Systemic and intestinal inflammatory biomarkers and indicators of $C$. difficile disease were measured in blood and fecal specimens to assess disease severity and the overall medical condition of the patient (Table 2). Thirty-two percent of subjects $(n=67)$ had $\mathrm{WBC}>15 \times$ $10^{9} / \mathrm{L}$. Serum albumin was measured in $77 \%$ of enrolled subjects $(n=162)$ and $20 \%$ of these subjects $(n=33)$ had low serum albumin levels $(\leq 2.5 \mathrm{~g} / \mathrm{dL})$. Creatinine levels were $\geq 1.5 \mathrm{mg} / \mathrm{dL}$ for $28 \%(n=59)$ of subjects. A majority of the cohort $(77 \% ; n=161)$ had elevated lactoferrin $(\geq 7.25 \mu \mathrm{g} / \mathrm{g}$ stool) and nearly half $(37 \% ; n=78)$ had lactoferrin levels over $100 \mu \mathrm{g} / \mathrm{g}$ stool. The frequency of each diagnostic parameter for the study cohort is listed in 
Table 3 Diagnostic parameters. Skew, median, minimum, and maximum are reported for continuous variables with skew above a magnitude of 1.5. Mean and standard deviation are reported for continuous variables with skew less than or equal to 1.5 in magnitude

\begin{tabular}{ll}
\hline Diagnostic parameters & Summary statistics \\
\hline $\begin{array}{l}\text { White blood cell count, skew, median } \\
\text { (minimum, maximum) }\end{array}$ & $1.7,11.4(0.2,53.9)$ \\
$\begin{array}{l}\text { Lactoferrin, skew, median (minimum, } \\
\text { maximum) }\end{array}$ & $3.3,48.5(0,2,823)$ \\
$\begin{array}{l}\text { Albumin level, mean (sd) } \\
\text { Creatinine, skew, median (minimum, } \\
\text { maximum) }\end{array}$ & $3.0(0.65)$ \\
\hline
\end{tabular}

Table 2 and the reported means or medians depending on the skew are listed in Table 3.

Each subject, all of whom were $\mathrm{PCR}+$ for $t c d B$, was placed in a group based on positive $(+)$ or negative $(-)$ toxigenic culture (tox culture) and stool toxin (tissue culture; TC). The diagnostic categories were: group 1 tox culture $(+)$ tissue culture $(+)(61 \% ; n=129)$, group 2 tox culture $(+)$ tissue culture (-) $(30 \% ; n=62)$, and group 3 tox culture $(-)$ tissue culture $(-)(9 \% ; n=19)$. Using this grouping, median fecal lactoferrin was significantly higher for group 1 subjects (90 $\mu \mathrm{g} / \mathrm{g}$ stool) compared with groups $2(24 \mu \mathrm{g} / \mathrm{g}$ stool $)$ and $3(20 \mu \mathrm{g} / \mathrm{g}$ stool; Wilcoxon rank sum $p<0.0001$ and $p=0.006$ respectively; Fig. 1). WBC median counts differed significantly between group $1\left(12.2 \times 10^{9} / \mathrm{L}\right)$ and $3\left(7.6 \times 10^{9} / \mathrm{L} ; p=0.003\right.$; Fig. 2). There were no differences observed among the three groups for serum albumin and serum creatinine.

A series of univariate logistic regression analyses were performed to assess the association with all-cause mortality within 100 days of CDI diagnosis. Table 4 shows odds ratios, confidence intervals, and $p$ values for the association between predictive variables and 100-day mortality. Age $(p<0.0001)$, Charlson co-morbidity index $(p=0.0002)$, ICU treatment $(p=0.0027), 027$ infection $(p=0.0271)$, WBC count $(p=0.0283)$, albumin $(p=0.0199)$, and the combination of 027 infection with stool toxin $(p=0.0059)$ showed significant associations with increased mortality. The variables in Table 4 were then used as candidate predictors of 100 day, all-cause mortality in a logistic regression model excluding albumin levels, which has substantially fewer observations than the other variables. A model selection was performed by enumerating all possible models formed from the ten candidate predictors, and the model with the lowest value of Bayesian Information Criteria (BIC) was chosen. This model selection revealed that age $(0<0.001)$, ICU treatment $(p=0.003)$, Charlson comorbidity index $(p<0.001)$ formed a model with the best trade-off between overall predictive ability of death and complexity as measured by BIC. The true-positive trade-off of this model was good, as measured by a $\mathrm{C}$-statistic $=0.774$, and supports these clinical characteristics as being significant in a high-risk patient population. When considering biomarkers for CDI, among the subjects who were stool toxin-positive, the subjects with $027 \mathrm{CDI}$ had a significantly higher mortality rate $(36 \% ; n=24)$ than that $(18 \% ; n=11)$ for subjects with non 027 infections $(p=0.017)$. The remaining groups, 027 - and non-027-infected subjects with no measurable stool toxin had mortality rates of $17 \%(n=18)$ vs $19 \%(n=62)$ respectively.

\section{Discussion}

In our study cohort, hospitalized patients with PCR-positive C. difficile infection having measurable stool toxin had significantly higher fecal lactoferrin and peripheral WBC, as indicators of more inflammation and severe CDI. Univariate analysis showed that age, Charlson co-morbidity index, ICU treatment, increased peripheral WBC, elevated lactoferrin,

\section{Group comparison - Lactoferrin}

Fig. 1 Comparison of lactoferrin median levels between diagnostic groups. Medians are noted with a bold line and bars and dots show lower and upper quartiles. Units for lactoferrin are shown in parenthesis. $p$ values not included in the plot are above 0.05

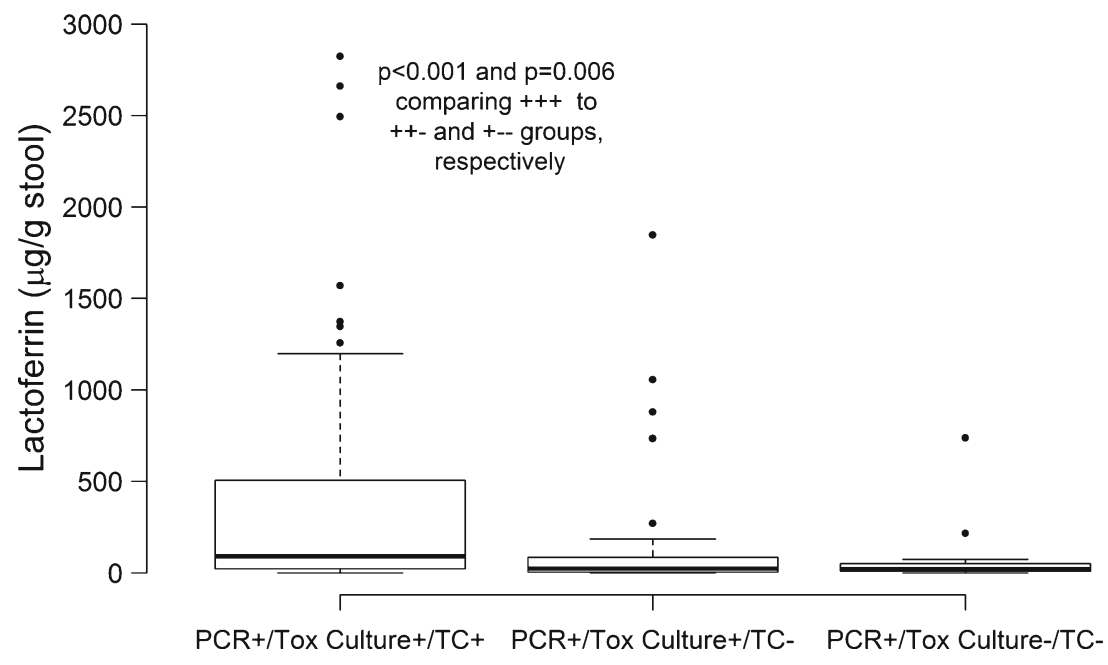


Fig. 2 Comparison of white blood cell (WBC) median counts in the diagnostic groups. Medians are noted with a bold line and, bars and dots show lower and upper quartiles. Units for WBC count are shown in parenthesis $p$ values not included in the plot are above 0.05

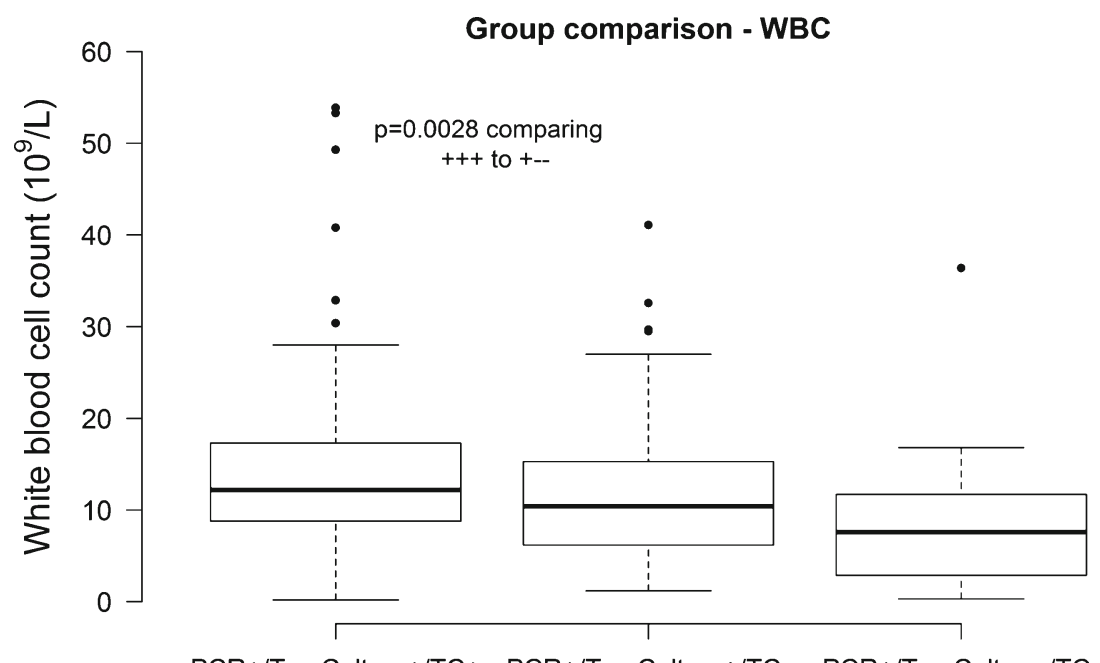

$\mathrm{PCR}+/$ Tox Culture+/TC+ PCR+/Tox Culture+/TC- PCR+/Tox Culture-/TC- decreased albumin, and elevated creatinine were significantly associated with death within 100 days of CDI diagnosis. Multiple studies have shown the link between stool toxin/ inflammation and severe CDI/mortality [23, 24, 37-39, 40, $45,46]$. In a study by Baker et al. [46], patients with CDI who were positive for stool toxin according to EIA had a mortality rate of $38 \%$ compared with $11 \%$ for patients who were PCRpositive/EIA-negative. They also showed that patients with stool toxin were also more likely to suffer with prolonged diarrhea $(2 ; p<0.001)$. In another study by Bloomfield et al. [26], blood parameters including WBC, serum albumin, creatinine, and C-reactive protein were assessed as risk factors for 30-day all-cause mortality in patients who were positive for stool toxin [26]. Based on a multivariate model, WBC $>15 \times 10^{9} / \mathrm{L}$ and serum albumin levels $<2.5 \mathrm{~g} / \mathrm{dL}$ were significantly associated with mortality. The patient cohort included in the study by Bloomfield et al. [26] was similar to our cohort and included hospitalized patients with a median age of 74 years, with $78 \%$ having a Charlson co-morbidity index score $>3$. Patients in our study were also older, with $44 \%$ of patients being over 65 years and $71 \%$ having a
Charlson co-morbidity index score of $>3$. Our results support the clinical association of having stool toxin with risk of death in older CDI patients and further show that these patients suffer more intestinal inflammation, as indicated by higher lactoferrin levels. In addition, we determined that patients infected with ribotype 027 in combination with stool toxin and higher lactoferrin had a significantly higher mortality rate than toxin-negative 027 -infected patients and all non-027 groups. Our logistic regression model using age, ICU treatment, and Charlson co-morbidity index was also successful at predicting death for this high-risk cohort $(\mathrm{C}$-statistic $=0.774)$. These findings contribute to the growing evidence that supports the clinical utility for both PCR and stool toxin detection in identifying patients with $C$. difficile disease for appropriate treatment. We also show results that confirm the significance for identifying the infecting ribotype in a high-risk population and raise an important question on whether this information would modify treatment and improve patient outcome.

Further studies are needed to determine the effects of toxin levels produced by ribotypes like ribotype 027 and the potential link between circulating toxin and mortality as described
Table 4 Univariate analysis for a combination of patient characteristics and fecal and blood biomarkers for an association with increased mortality. $p$ values $\geq 0.05$ are considered significant

\begin{tabular}{lccccc}
\hline Effect & Odds ratio est & Lower CL & Upper CL & Prob Chi Sq & $n$ \\
\hline Age & 1.051 & 1.025 & 1.077 & $<0.0001$ & 210 \\
Sex & 0.729 & 0.385 & 1.381 & 0.3319 & 210 \\
Charlson index & 1.235 & 1.105 & 1.38 & 0.0002 & 210 \\
ICU & 2.737 & 1.416 & 5.29 & 0.0027 & 210 \\
027 CDI & 2.064 & 1.086 & 3.926 & 0.0271 & 210 \\
WBC & 1.038 & 1.004 & 1.073 & 0.0283 & 209 \\
Lactoferrin & 1.000 & 1.000 & 1.001 & 0.1407 & 210 \\
Albumin & 0.503 & 0.282 & 0.897 & 0.0199 & 162 \\
Creatinine & 1.019 & 0.828 & 1.254 & 0.8577 & 207 \\
027 and stool toxin + & 2.512 & 1.304 & 4.839 & 0.0059 & 210 \\
All stool toxin + & 1.638 & 0.828 & 3.239 & 0.1561 & 210 \\
\hline
\end{tabular}


recently in an animal model study by Kuehne et al. [47]. In this recent study, stain R20291, which produces toxins A and $B$ along with binary toxin (CDT), was mutated to have combinations of toxins $\mathrm{A}$ and $\mathrm{B}$, and CDT expression to assess the role of CDT in causing disease. Interestingly, the mutant strain only expressing CDT killed 3 out of 9 infected hamsters. Disease presentation in these animals was atypical and only included wet tail and evidence of small bowel inflammation. The authors went on to conclude that these results suggest the role of increased virulence for $C$. difficile strains like ribotype 027 with binary toxin [47]. In another study by Koon et al. [48], human colonic biopsies and isolated human monocytes were used to show induced expression of the inflammatory cytokines TNF $\alpha$ and IL- $\beta$ by toxins A and B. In addition, infusions with monoclonal antibodies against toxin $\mathrm{A}$ and $\mathrm{B}$ were used to reduce the cytokine levels and protect epithelial cells from damage in human colonic tissue [48]. Our findings, along with these recent studies, further confirm the role of C. difficile toxin in causing intestinal inflammation and tissue damage, leading to a higher risk of death. In our patient cohort, 027-infected patients may have higher amounts of stool toxin, possibly causing systemic disease and death. Further studies are needed to determine the effects of toxin levels produced by ribotypes like ribotype 027 and the potential link between circulating toxin and mortality.

Our study confirms the clinical relevance of detecting stool toxin in patients who are PCR-positive for $C$. difficile. Patients with stool toxin, elevated lactoferrin, and infected with ribotype 027 are at an increased risk of death. A combination of clinical criteria, blood and fecal biomarkers for disease severity, and identifying the infecting ribotype should be considered in the evaluation of older, sicker patients with suspected CDI.

Acknowledgements Partial funding for this study was provided by TechLab, Inc. and NIH/NIAD grant (5K23AI074681).

\section{Conflict of interest Authors include scientists from TechLab, Inc.}

Open Access This article is distributed under the terms of the Creative Commons Attribution License which permits any use, distribution, and reproduction in any medium, provided the original author(s) and the source are credited.

\section{References}

1. Redelings MD, Sorvillo F, Mascola L (2007) Increase in Clostridium difficile-related mortality rates, United States, 1999-2004. Emerg Infect Dis 13(9):1417-1419

2. Goorhuis A, Debast SB, Dutilh JC, van Kinschot CM, Harmanus C, Cannegieter SC et al (2011) Type-Specific risk factors and outcomes in an outbreak with 2 different Clostridium difficile types simultaneously in 1 hospital. Clin Infect Dis 53(9):860-869

3. Hensgens MP, Goorhuis A, Dekkers OM, van Benthem BH, Kuijper EJ (2013) All-cause and disease-specific mortality in hospitalized patients with Clostridium difficile infection: a multicenter cohort study. Clin Infect Dis 56(8):1108-1116

4. Hubert B, Loo VG, Bourgault AM, Poirier L, Dascal A, Fortin E et al (2007) A portrait of the geographic dissemination of the Clostridium difficile North American pulsed-field type 1 strain and the epidemiology of $C$. difficile-associated disease in Quebec. Clin Infect Dis 44:237-244

5. Labbe A, Poirier L, MacCannell D, Louie T, Savoie M, Beliveau C, Laverdiere M, Pepin J (2008) Clostridium difficile infections in a Canadian tertiary care hospital before and during a regional epidemic associated with the BI/NAP1/027 strain. Agents Chemother 52(9): 3180-3187

6. Loo VG, Poirier L, Miller MA, Oughton M, Libman MD, Michaud S et al (2005) A predominantly clonal multi-institutional outbreak of Clostridium difficile-associated diarrhea with high morbidity and mortality. N Engl J Med 353:2442-2449

7. Morgan OW, Rodrigues B, Elston T, Verlnader NQ, Brown DF, Brazier J et al (2008) Clinical severity of Clostridium difficile PCR ribotype 027: a case-case study. PLoS One 3:1-6

8. Muto CA, Pokrywka M, Shutt K, Mendelsohn AB, Nouri K, Posey K et al (2005) A large outbreak of Clostridium difficile-associated disease with an unexpected proportion of deaths and colectomies at a teaching hospital following increased fluoroquinolone use. Infect Control Hosp Epidemiol 26(3):273-280

9. Pepin J, Saheb N, Coulombe M, Alary M, Corriveau M, Authier S et al (2005) Emergence of fluoroquinolones as the predominant risk factor for Clostridium difficile-associated diarrhea: A cohort study during an epidemic in Quebec. Clin Infect Dis 41:1254-1260

10. Carlson PE, Walk ST, Bourgis AE, Liu M, Kopliku F, Lo E (2013) The relationship between phenotype, ribotype, and clinical disease in human Clostridium difficile isolates. Anaerobe 24:109-116

11. Merrigan M, Venugopal A, Mallozzi M, Roxas B, Viswanathan VK, Johnson S et al (2010) Human hypervirulent Clostridium difficile strains exhibit increased sporulation as well as robust toxin production. J Bacteriol 192(19):4904-4911

12. Moore P, Kyne L, Martin A, Solomon K (2013) Germination efficiency of clinical Clostridium difficile spores and correlation with ribotype, disease severity and therapy failure. J Med Microbiol 62(Pt 9):1405-1413

13. O'Connor JR, Johnson S, Gerding D (2009) Clostridium difficile infection caused by epidemic BI/NAP1/027 Strain. Gastroenterology 136:1913-1924

14. Vohra P, Poxton IR (2011) Comparison of toxin and spore production in clinically relevant strains of Clostridium difficile. Microbiology 157:1343-1353

15. Warny M, Pepin J, Fang A, Killgore G, Thompson A, Brazier J et al (2005) Toxin production by an emerging strain of Clostridium difficile associated with outbreaks of severe disease in North America and Europe. Lancet 366(9491):1079-1084

16. Barbut F, Rupnik M (2012) 027, 078 and others: going beyond the numbers (and away from the hypervirulence). Clin Infect Dis 55(12): $1669-1672$

17. Cloud J, Noddin L, Pressman A, Hu M, Kelly C (2009) Clostridium difficile strain NAP-1 is not associated with severe disease in a nonepidemic setting. Clin Gastro and Hep 7:868-873

18. Gerding D, Johnson S (2013) Does infection with specific Clostridium difficile strains or clades influence clinical outcome? Clin Infect Dis 56(11):1601-1603

19. Sirard S, Valiquette L, Fortier L (2011) Lack of association between clinical outcome of Clostridium difficile infections, strain type, and virulence-associated phenotypes. J Clin Microbiol 49(12):4040-4046

20. Walk ST, Micic D, Jain R, Lo ES, Trivedi I, Liu EW et al (2012) Clostridium difficile ribotype does not predict severe infection. Clin Infect Dis 55(12):1661-1668

21. Burnham CD, Carroll KC (2013) Diagnosis of Clostridium difficile infection: an ongoing conundrum for clinicians and for clinical laboratories. Clin Micro Rev 26(3):604-630 
22. Crobach MJ, Dekkers OM, Wilcox MH, Kuijper EJ (2009) European Society of Clinical Microbiology and Infectious Diseases (ESCMID): Data review and recommendations for diagnosing Clostridium difficileinfection (CDI). Clin Microbiol Infect 15:1053-1066

23. Planche TD, Davies KA, Coen PG, Finney JM, Monohan IM, Morris KA et al (2013) Differences in outcome according to Clostridium difficile testing method: a prospective multicentre diagnostic validation study of $C$. difficile infection. Lancet Infect Dis 13(11):936-945

24. Polage CR, Chin DL, Leslie JL, Tang J, Cohen SH, Solnick JV (2012) Outcomes in patients tested for Clostridium difficile toxins. Diagn Microbiol Infect Dis 74(4):369-373

25. Bhangu A, Czapran A, Bhangu S, Pillay D (2010) Optimum timing of blood tests for monitoring patients with Clostridium difficile-associated diarrhea. J Investig Med 58(4):621-624

26. Bloomfield MG, Sherwin JC, Gkrania-Klotsas E (2012) Risk factors for mortality in Clostridium difficile infection in the general hospital population: a systematic review. J Hosp Infect 82:1-12

27. Cohen SH, Gerding DN, Johnson S, Kelly CP, Loo VG, McDonald LC et al (2010) Clinical Practice Guidelines for Clostridium difficile Infection: 2010 Update by the Society for Healthcare Epidemiology of America (SHEA) and the Infectious Diseases Society of America (IDSA). Infect Control Hosp Epidemiol 31(5):431-455

28. Fujitani S, George WL, Murthy AR (2011) Comparison of clinical severity score indices for Clostridium difficile infection. Infect Control Hosp Epidemiol 32(3):220-228

29. Henrich TJ, Krakower D, Bitton A, Yokoe DS (2009) Clinical risk factors for severe Clostridium difficile-associated disease. Emerg Infect Dis 15(3):415-422

30. Pant C, Madonia P, Minocha A, Manas K, Jordan P, Bass P (2009) Laboratory markers as predictors of mortality in patients with Clostridium difficile infection. J Investig Med 57(8):1-3

31. Surawicz CM, Brandt L, Binion DG, Ananthakrishnan AN, Curry SR, Gilligin PH et al (2013) Guidelines for diagnosis, treatment, and prevention of Clostridium difficile infection. Am J Gastroenterol 108:478-498

32. Walker AS, Eyre DW, Wyllie DH, Dingle KE, Griffiths D, Shine B et al (2013) Relationship between bacterial strain type, host biomarkers and mortality in Clostridium difficile infection. Clin Infect Dis 56(11): $1589-1600$

33. Guerrant RL, Araujo V, Soares E, Kotloff K, Lima A, Cooper W, Lee A (1992) A measurement of fecal lactoferrin as a marker of fecal leukocytes. J Clin Microbiol 30:1238-1242

34. Pawlowski SW, Archbald-Pannone L, Carman RJ, Alcantara-Warren C, Lyerly D, Genheimer CW et al (2009) Elevated levels of intestinal inflammation in Clostridium difficile infection associated with fluoroquinolone-resistant C. difficile. J Hosp Infect 73(2):185-187

35. Schleupner MA, Garner DC, Sosnowski KM, Scheulpner CJ, Barrett LJ, Silva DH et al (1995) Concurrence of Clostridium difficile toxin A enzyme-linked immunosorbent assay, fecal lactoferrin assay, and clinical criteria with cytotoxin titer in two patient cohorts. J Clin Microbiol 33:1755-1759
36. Wren MW, Sivapalan M, Kinson R, Shetty NR (2009) Laboratory diagnosis of Clostridium difficile infection. An evaluation of tests for faecal toxin, glutamate dehydrogenase, lactoferrin and toxigenic culture in the diagnostic laboratory. Br J Biomed Sci 66(1):1-5

37. Boone JH, DiPersio JR, Tan MJ, Salstrom S-J, Wickham KN, Carman RJ et al (2013) Elevated lactoferrin is associated with moderate to severe Clostridium difficile disease, stool toxin, and 027 infection. Eur J Clin Microbiol Infect Dis. doi:10.1007/s10096-0131905-X

38. Feghaly RE, Stauber JL, Deych E, Gonzalez C, Tarr P, Haslam D (2013) Markers of intestinal inflammation, not bacterial burden, correlate with clinical outcomes in Clostridium difficile infection. Clin Infect Dis 56(12):1713-1721

39. LaSala PR, Ekhmimi T, Hill AK, Farooqi I, Perrotta PL (2013) Quantitative fecal lactoferrin in toxin-positive and toxin-negative Clostridium difficile specimens. J Clin Microbiol 51(1):311-313

40. Yacyshyn MB, Yacyshyn B (2013) The role of gut inflammation in recurrent CDAD. Clin Infect Dis 56(12):1722-1730

41. Charlson ME, Pompei P, Ales KL, MacKenzie CR (1986) A new method of classifying prognostic comorbidity in longitudinal studies: Development and validation. J Chron Dis 40(5):373-383

42. Drekonja DM, Rector TS, Cutting A, Johnson JR (2013) Urinary tract infection in male veterans: treatment patterns and outcomes. JAMA Intern Med 173(1):62-68

43. Boone JH, Goodykoontz M, Rhodes SJ, Price K, Smith J, Gearhart $\mathrm{KN}$ et al (2012) Clostridium difficile prevalence rates in a large healthcare system stratified according to patient population, age, gender, and specimen consistency. Eur J Clin Microbiol Infect Dis 31(7):1551-1559

44. Stubbs SL, Brazier JS, O'Neill GL, Duerden BI (1999) PCR targeted to the 16S-23S rRNA gene intergenic spacer region of Clostridium difficile and construction of a library consisting of 116 different PCR ribotypes. J Clin Microbiol 37:461-463

45. Akerlund T, Svenungsson B, Lagergren A, Burman L (2006) Correlation of disease severity with fecal toxin levels in patients with Clostridium difficile-associated diarrhea and distribution of PCR ribotype and toxin yields in vitro of corresponding isolates. J Clin Microbiol 44(2):353-358

46. Baker I, Leeming JP, Reynolds R, Ibrahim I, Darley E (2013) Clinical relevance of a positive molecular test in the diagnosis of Clostridium difficile infection. J Hosp Infect 4(4):311-315

47. Kuehne S, Collery M, Kelly M, Cartman S, Cockayne A, Menton N (2014) The importance of toxin A, toxin B and CDT in virulence of an epidemic Clostridium difficile strain. J Infect Dis 209(1):83-86

48. Koon HW, Shih DQ, Hing TC, Yoo JH, Ho S, Chen X et al (2013) Human monoclonal antibodies against Clostridium difficile toxins A and $\mathrm{B}$ inhibit inflammatory and histologic responses to the toxins in human colon and peripheral blood monocytes. Antimicrobiol Agents Chemother 57(7):3214-3223 